\title{
Fuzzy System Based Load Frequency Control of Hydro-Thermal -Thermal Interconnected Power System
}

\author{
Dr. Anand Gondesi \\ Assistant Professor \\ Department of EEE \\ Dr. Lankapalli Bullayya College of Engineering \\ $\&$ \\ Dr. Varaha Narasimha Raja. Ch \\ Assistant Professor \\ Department of EEE \\ Anil Neerukonda Institute of Technology \& Sciences (A) \\ Visakhapatnam, Andhra Pradesh, India
}

\begin{abstract}
Today, in power systems the Load Frequency Control (LFC) problem plays a vital role in an interconnected power system, wherein it maintains the system frequency and tie line flow at their scheduled values during normal period. It is due to frequency of power system, which changes over time with respect to continuous load variation. The present chapter proposes a new methodology to study the Load Frequency Control (LFC) problem of a three area inter-connected system using R Fuzzy system (FS) approach. Moreover, this technique is applied to control the systems which include three areas considering a non-linearity Generation Rate constraint (GRC) having two steam turbines and one hydro-turbine tied together. The main advantage of this controller is its high insensitivity to large load changes and plant parameter variations even in the presence of non-linearity. Furthermore, it is tested on a three-area power system to illustrate its robust performance. The results obtained by using Rule Based Fuzzy PID controller explicitly show that the performance of this proposed controller is superior to conventional controller in terms of several parameters like overshoot, settling time and robustness.
\end{abstract}

Keywords: Load Frequency Control, Reliability, Fuzzy Controller, Power System.

\section{Introduction}

Today, due to rise in the demand for electric power, electric power system is becoming more and more complicated. The power system operates in normal state, which is characterized by constant frequency and voltage profile with certain system reliability. Therefore, the supply of electric power with stability and high 
reliability is required. Under dynamic operation of power system, decentralization of control action to individual areas is important. Load Frequency Control (LFC) is a very important issue in power system operation control for supplying sufficient and reliable electric power with good quality. An interconnected power system is a combination of different control areas, in which two areas are connected together with a transmission line called tie-line. In each control area, all generators are assumed to form a coherent group. The power system is subjected to local variations of random magnitude and duration. Moreover, the satisfactory operation of a power system, the frequency and tie-line deviations should be maintained within the specified tolerance. The frequency of a system depends on active power balance. As frequency is a common factor throughout the system, a change in active power demand at one point is reflected throughout the system.

\section{Objectives}

$>$ To develop mathematical models for multi-area power system

$>$ To devise and implement PID and fuzzy Load Frequency controllers for multi area interconnected power systems

\section{Literature Survey}

The coherent areas are interconnected through tie lines which are used for contractual energy exchange between areas and provide inter-area support during abnormal operations (Talaq \& Al-Basri, 1998) Automatic Generation Control (AGC) or Load Frequency Control (Chaturvedi, Satsangi \& Kalra, 1999; Chown \& Hartman, 1998) is a very important issue in power system operation and control for supplying sufficient and reliable electric power with good quality. In large interconnected power system, thermal, hydro, nuclear and gas power units generate large amount of power. The gas power plants, tidal power plants, nuclear power plants, etc. produces a very small percentage of total system generation. Hence, such plants do not play a significant role LFC of large power system and gas plants are used to meet peak demands only. Thus, the natural choice for LFC falls on either thermal or hydro units. Also, it is observed that most of the earlier works in the area of LFC pertain to interconnected thermal systems and relatively lesser attention has been devoted to the LFC of an interconnected hydro-thermal system (Sudha \& Santhi, 2012) involving thermal and hydro subsystem of widely different characteristics. Concordia and Kirchmayer have given the LFC of a hydro-thermal system (Sudha, Raju \& Sekhar, 2012) considering non-reheat type thermal system neglecting non-linearity like generation rate constraints. This has been observed by Nanda, Kothari and Satsangi in 1983, wherein they presented the comprehensive analysis of AGC (Khamsum et al. 2006) of an interconnected hydrothermal system in continuous-discrete mode with classical controllers. Usually, the hydro system uses a mechanical governor and the thermal system uses reheat turbine in an interconnected hydro-thermal system. It is over decades, intelligent controllers like 
Fuzzy Logic Controllers (FLCs) have been successfully developed for analysis and control of nonlinear systems (Indulkar \& Raj, 1995; Shayeghi, Jalili \& Shayanfar, 2005). The major advantage of this fuzzy reasoning approach is motivated to handle ambiguous information, like uncertainties in available knowledge (Chang \& Fu, 1997; Indulkar \& Raj 1995; Gayadhar, Sidhartha \& Ardil, 2009) proposed different fuzzy scheduling schemes for conventional PI and/or PID controllers. These methods provide good performances under steady state but the system transient and dynamic responses are relatively. Moreover, the main objective of this research is to determine Load Frequency Control problem for a multi area power system, wherein taking into consideration the uncertainties in the parameters of power system. Thus, to solve this problem, many researchers have proposed basic fuzzy logic-based controllers to power systems (Mendel, 2000; Nanda \& Sakkaram, 2003) and termed as classical or Type-1 fuzzy.

\section{Problem Identification}

The main goals of Load Frequency Control (LFC) are to maintain frequency and to control change in tie-line power between control areas. In furtherance, the conventional controllers do not take into consideration due to inherent nonlinearities of different power system components. They also failed to adapt the controller gains with change in operating points.

\section{Methodology}

A power system is made up of several sub-systems, which are used to deliver electricity from generation to consumption. It is important to see that frequency of all areas in a steady state remains identical. The LFC is a control method that ensures all areas in steady state have zero change in frequency and tie-line power deviations. Moreover, in this present research study work fuzzy logic controllers are implemented for large scale power systems which are distributed into for LFC problem.

\section{Modeling of Power System \& Problem Formulation}

Usually, a large-scale power system consists of different complicated nonlinear models. It constitutes of number of inter-connected control areas, which are linked by tie-lines power, but to design LFC, a simplified and linearized model is employed. The detailed block structure consisting of two steam turbines and one hydro -turbine tied together through power lines of multi area power system including Generation Rate Constraint (GRC) for load frequency control has been investigated in this chapter as shown in fig. 1 with Area Control Error (ACE) and its derivatives are given as the inputs to controllers. 


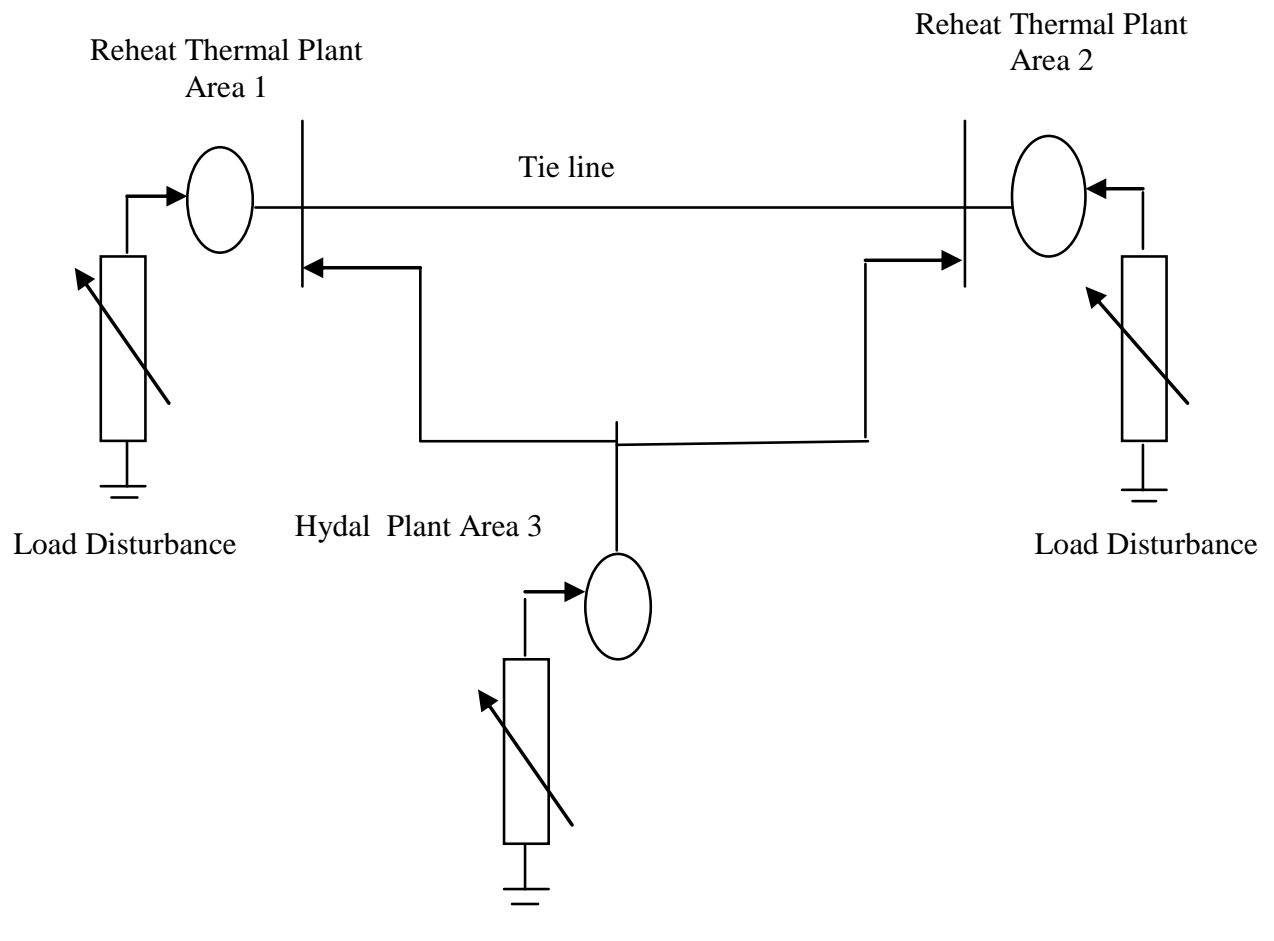

Load Disturbance

Fig. 1: Three - Area Interconnected Power System

The detailed block diagram of interconnected power system model is shown in figure 2, wherein the parameters of three areas are given in Appendix (Surya Prakash \& Sinha, 2011). Also, the modeling of speed governors and turbines are discussed in (Kothari, Kauld \& Nanda, 1980). The power generation can change only at a specified maximum rate for steam plants. Hence, in order to restrict the generation rate for steam plants, limiters are added to the governors. A typical value of Generation Rate Constraint (GRC) for thermal units of 3 percent / min is considered. The two limiters, bounded by \pm 0.0005 are used within the LFC to prevent the excessive control action. The generation rate constraints for all the areas are taken into account by adding limiters to the turbines. 


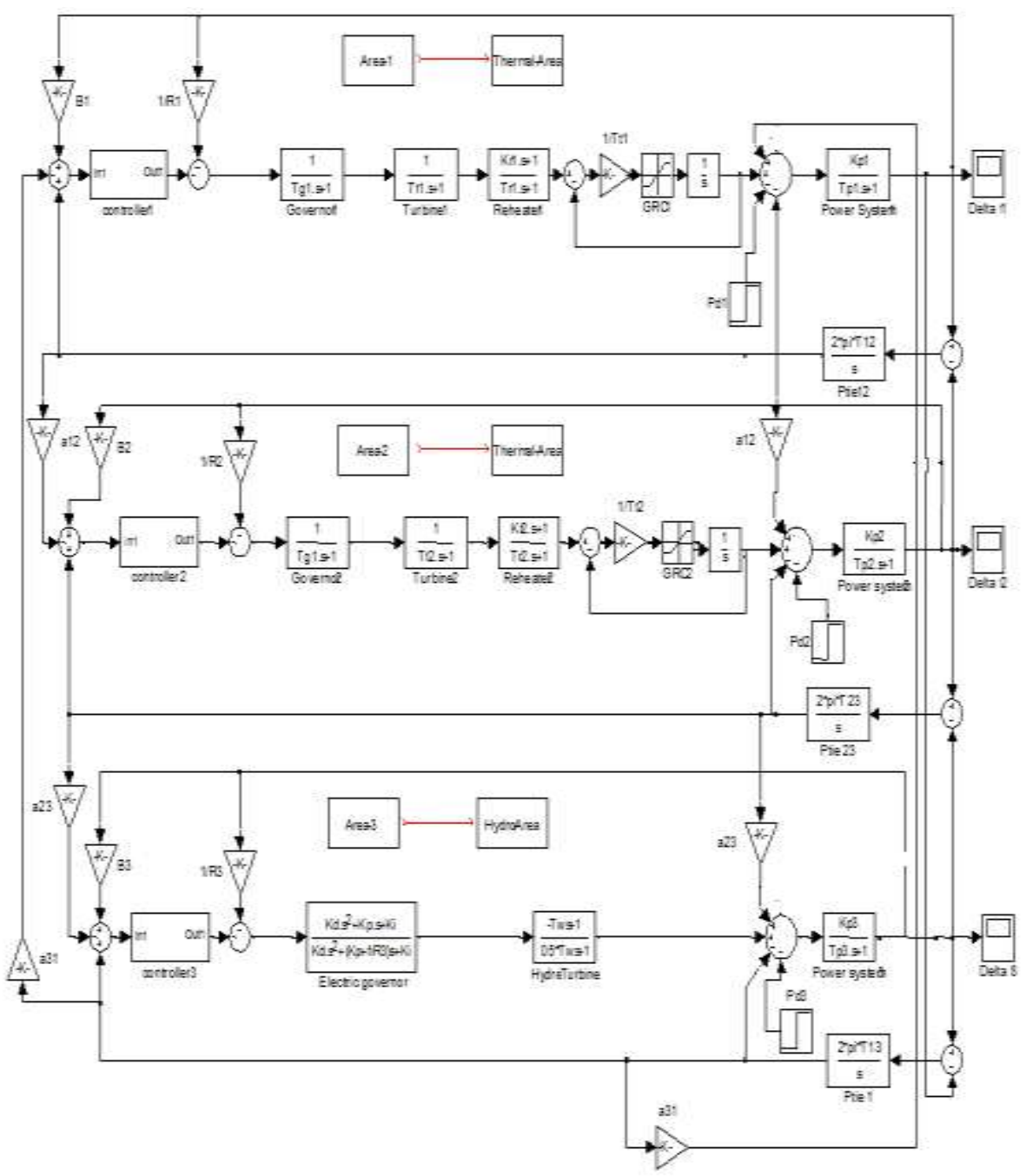

Fig. 2: Block Diagram of Three Area Interconnected system

\section{Fuzzy Logic controllers}

Fuzzy logic controllers have no fixed structure like conventional PI, PD and PID controllers because there is still no well-defined criteria for deciding on the shape of MF's, the number of linguistic values, the standard rule base, the most appropriate inference mechanism and defuzzification strategy. This is probably due to these aforementioned reasons with regard difficulties in designing an FLC analytically (Sudha \& Santhi, 2012). The structure of a Fuzzy PI controller preserves the basic properties and merits of general PI controller. It has four simple fuzzy IF-THEN rules. The basic characteristics of proposed design may differ from other fuzzy or non-fuzzy PID-type controllers, which include the following aspects: 
1. It has the same linear structure as the conventional PI controller, but has variable gains; the proportional and integral gains are non- linear functions of the input signals.

2. The controller is designed based on the precise mathematical model of a discrete PI controller, from which the fuzzy control law is derived.

3. Membership functions are simple symmetric trapezoidal and asymmetrical trapezoidal, which use only four fuzzy logic IF-THEN rules with two membership functions in each input and use eight fuzzy logic IF-THEN rules with three membership functions in each input.

4. The Fuzzification, control-rule execution and defuzzification steps are all embedded in the final product of fuzzy control law, which is an explicit conventional formula, so that the fuzzification-rules-defuzzification routine is not needed for all the process control steps.

The performance of conventional PID controller is considered to be quite adequate for linear first order system with the small-time delay. However, its performance for a system with large time delay and also for a nonlinear system may be very poor due to large overshooting and excessive oscillation (Sudha \& Santhi, 2012). To improve the performance of a conventional PID controller, engineers have tried to use fuzzy PID controller instead of classical ones. Ying has developed the fuzzy PID controller (Castillo, Urias \& Mellin, 2007). He also suggested that the improvement is actually due to the nonlinearity of fuzzy PID controller (Sudha \& Santhi, 2012). The present work is an attempt to analyze in detail the derivation of analytical structure of fuzzy controllers using Trapezoidal MFs (Symmetrical and asymmetrical). To show the effectiveness of fuzzy controllers over conventional controllers' time delay systems and nonlinear systems are considered for simulations. As a case study of dc motor along with saturation non-linearity, an aircraft attitude-control system and high-speed steel-rolling mill are considered and simulations are carried out to demonstrate the superiority of Fuzzy PID controllers over the conventional PID controller have done by using symmetric and asymmetrical Trapezoidal membership sets in input and output. 


\section{Table 1: Control Rules for Fuzzy Controller}

\begin{tabular}{|c|c|}
\hline Rule-1 & If $x(\dot{\delta})$ is $\mathrm{P}$ and $x(\delta)$ is $\mathrm{P}$ and $x(\ddot{\delta})$ is $\mathrm{P}$ then output is $\mathrm{NB}$ \\
\hline Rule-2 & If $x(\dot{\delta})$ is $\mathrm{P}$ and $x(\delta)$ is $\mathrm{P}$ and $x(\ddot{\delta})$ is $\mathrm{N}$ then output is NS \\
\hline Rule-3 & If $x(\dot{\delta})$ is $\mathrm{P}$ and $x(\delta)$ is $\mathrm{P}$ and $x(\ddot{\delta})$ is $\mathrm{Z}$ then output is $\mathrm{NM}$ \\
\hline Rule-4 & If $x(\dot{\delta})$ is $\mathrm{P}$ and $x(\delta)$ is $\mathrm{N}$ and $x(\ddot{\delta})$ is $\mathrm{P}$ then output is NM \\
\hline Rule-5 & If $x(\dot{\delta})$ is $\mathrm{P}$ and $x(\delta)$ is $\mathrm{N}$ and $x(\ddot{\delta})$ is $\mathrm{Z}$ then output is $\mathrm{Z}$ \\
\hline Rule-6 & If $x(\dot{\delta})$ is $\mathrm{P}$ and $x(\delta)$ is $\mathrm{N}$ and $x(\ddot{\delta})$ is $\mathrm{N}$ then output is $\mathrm{NS}$ \\
\hline Rule-7 & If $x(\dot{\delta})$ is $\mathrm{P}$ and $x(\delta)$ is $\mathrm{Z}$ and $x(\ddot{\delta})$ is $\mathrm{P}$ the \\
\hline Rule-8 & If $x(\dot{\delta})$ is $\mathrm{P}$ and $x(\delta)$ is $\mathrm{Z}$ and $x(\ddot{\delta})$ is Z then output is NS \\
\hline Rule-9 & If $x(\dot{\delta})$ is $\mathrm{P}$ and $x(\delta)$ is $\mathrm{Z}$ and $x(\ddot{\delta})$ is $\mathrm{N}$ then output is $\mathrm{Z}$ \\
\hline Rule-10 & If $x(\dot{\delta})$ is $\mathrm{N}$ and $x(\delta)$ is $\mathrm{P}$ and $x(\ddot{\delta})$ is $\mathrm{P}$ then $\mathrm{o}$ \\
\hline Rule-11 & If $x(\dot{\delta})$ is $\mathrm{N}$ and $x(\delta)$ is $\mathrm{P}$ and $x(\ddot{\delta})$ is $\mathrm{Z}$ then \\
\hline Rule-12 & If $x(\dot{\delta})$ is $\mathrm{N}$ and $x(\delta)$ is $\mathrm{P}$ and $x(\ddot{\delta})$ is $\mathrm{N}$ then $\mathrm{o}$ \\
\hline Rule-13 & If $x(\dot{\delta})$ is $\mathrm{N}$ an \\
\hline Rule-14 & If $x(\dot{\delta})$ is $\mathrm{N}$ and $x(\delta)$ is $\mathrm{N}$ a \\
\hline Rule-15 & If $x(\dot{\delta})$ is $\mathrm{N}$ and $x(\delta)$ is $\mathrm{N}$ and $x(\ddot{\delta})$ is $\mathrm{Z}$ then $\mathrm{c}$ \\
\hline Rule-16 & If $\mathrm{x}(\dot{\delta})$ is $\mathrm{N}$ and $\mathrm{x}(\delta)$ is $\mathrm{Z}$ and $\mathrm{x}(\ddot{\delta})$ is $\mathrm{P}$ then output is $\mathrm{Z}$ \\
\hline Rule-17 & If $x(\dot{\delta})$ is $\mathrm{N}$ and $x(\delta)$ is $\mathrm{Z}$ and $x(\ddot{\delta})$ is $\mathrm{Z}$ then output is PS \\
\hline Rule-18 & If $x(\dot{\delta})$ is $\mathrm{N}$ and $x(\delta)$ is $\mathrm{Z}$ and $x(\ddot{\delta})$ is $\mathrm{N}$ then output is PM \\
\hline Rule-19 & If $x(\dot{\delta})$ is $\mathrm{Z}$ and $x(\delta)$ is $\mathrm{P}$ and $x(\ddot{\delta})$ is $\mathrm{P}$ then output is $\mathrm{NM}$ \\
\hline Rule-20 & If $x(\dot{\delta})$ is $\mathrm{Z}$ and $x(\delta)$ is $\mathrm{P}$ and $x(\ddot{\delta})$ is $\mathrm{N}$ then \\
\hline Rule-21 & ad $x(\ddot{\delta})$ is $\mathrm{Z}$ th \\
\hline Rule-22 & If $x(\dot{\delta})$ is $\mathrm{Z}$ and $x(\delta)$ is $\mathrm{N}$ a \\
\hline Rule-23 & If $x(\dot{\delta})$ is Z and $x(\delta)$ is $\mathrm{N}$ and $x(\ddot{\delta})$ is $\mathrm{N}$ then output is PM \\
\hline Rule-24 & If $x(\dot{\delta})$ is $\mathrm{Z}$ and $x(\delta)$ is $\mathrm{N}$ and $x(\ddot{\delta})$ is $\mathrm{Z}$ then output is PS \\
\hline Rule-25 & If $x(\dot{\delta})$ is Z and $x(\delta)$ is Z and $x(\ddot{\delta})$ is $\mathrm{P}$ then output is NS \\
\hline Rule-26 & If $x(\dot{\delta})$ is $\mathrm{Z}$ and $x(\delta)$ is $\mathrm{Z}$ and $x(\ddot{\delta})$ is $\mathrm{Z}$ then output is $\mathrm{Z}$ \\
\hline Rule-27 & If $x(\dot{\delta})$ is $\mathrm{Z}$ and $x(\delta)$ is $\mathrm{Z}$ and $x(\ddot{\delta})$ is $\mathrm{N}$ then output is PS \\
\hline
\end{tabular}

\section{Simulation Results}

The frequency deviation of the first area, $\Delta \mathrm{f}_{1}$, the frequency deviation of the second area, $\Delta f_{2}$ and the frequency deviation of the third area, $\Delta f_{3}$ signals of the closed-loop system are shown in figures 3 to 5 . Using proposed method, the frequency deviations and inter area tie power is quickly driven back to zero and the controller designed using Type-1fuzzy controller has the best performance in control and damping of frequency and tie-power in all responses when compared with conventional PID Controller. 
Holistic Research Perspectives Vol.5

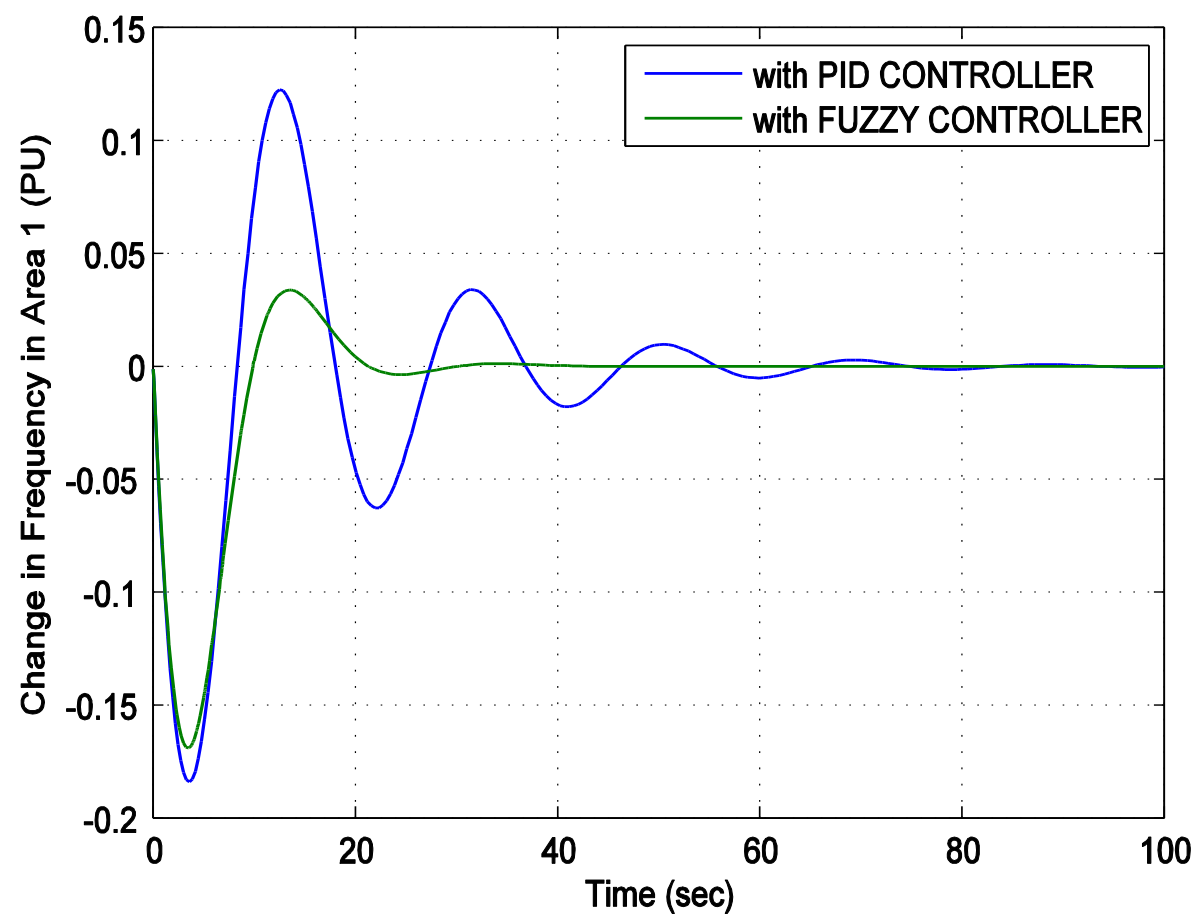

Fig.3: Change in Frequency Deviation in Area 1

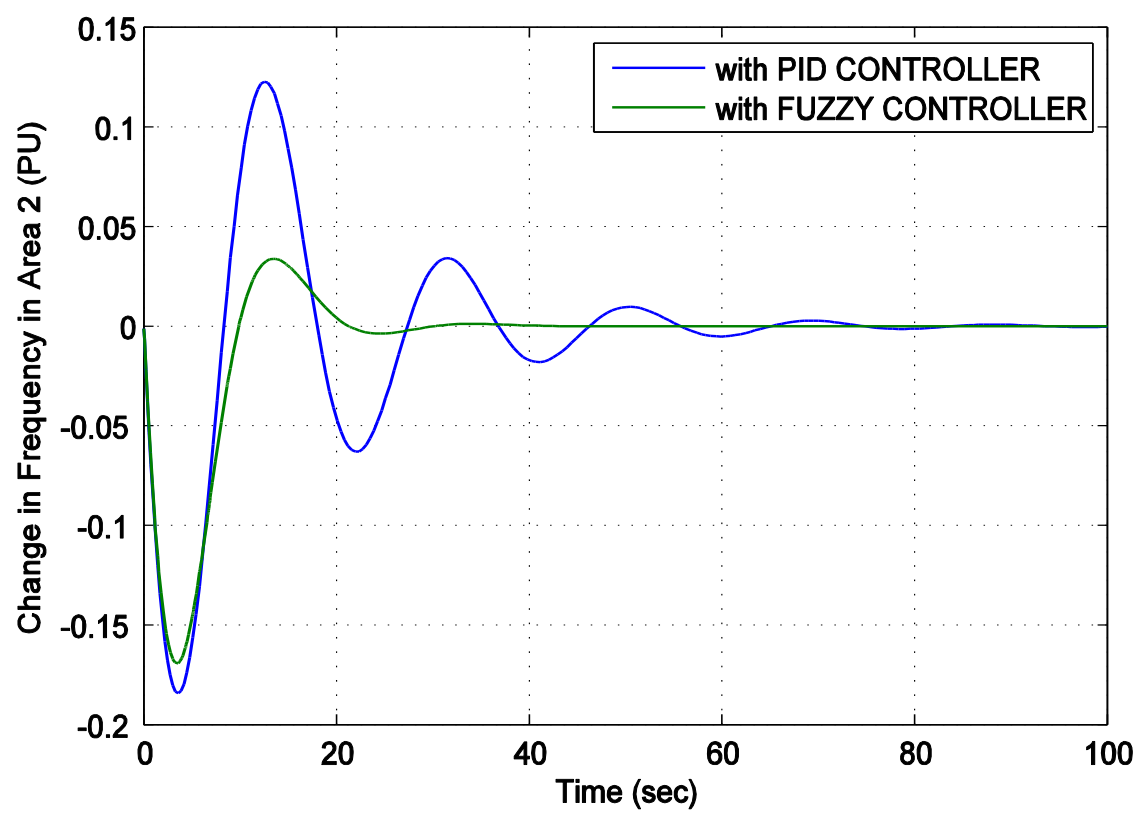

Fig.4: Change in Frequency Deviation in Area 2 


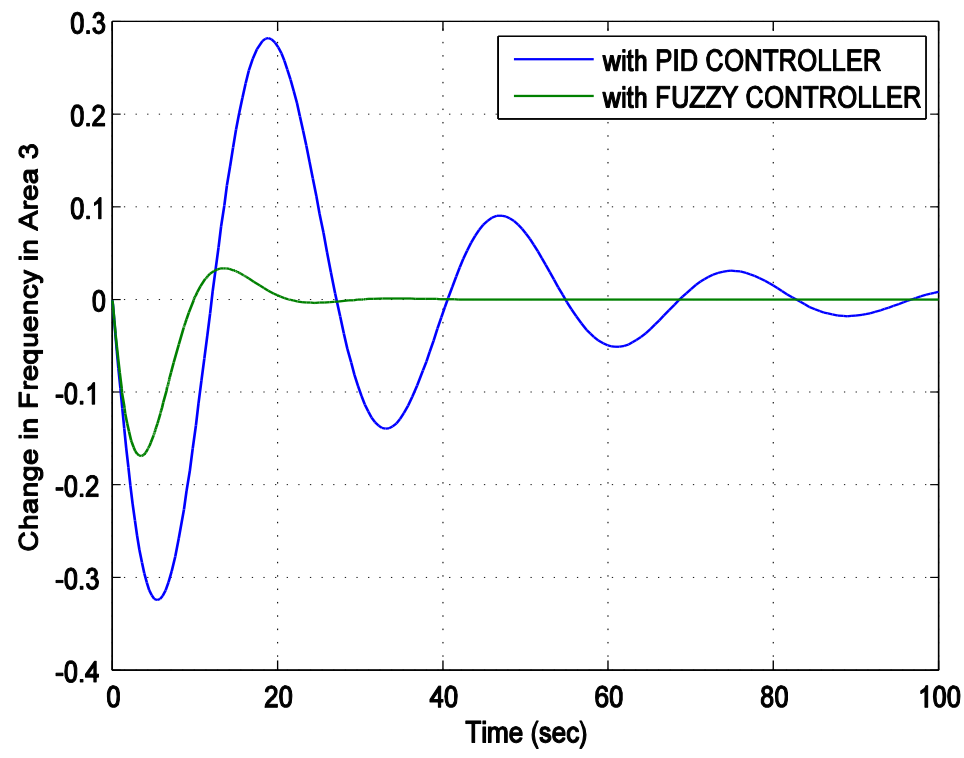

Fig.6: Change in Frequency Deviation in Area 3

Table 2: Frequency response in various control strategies

\begin{tabular}{|c|c|c|c|c|}
\hline Frequency & Controller & $\begin{array}{c}\text { Peak } \\
\text { Overshoot }\end{array}$ & $\begin{array}{c}\text { Peak } \\
\text { Undershoot }\end{array}$ & $\begin{array}{c}\text { Settling } \\
\text { Time } \\
\text { (Sec) }\end{array}$ \\
\hline $\begin{array}{c}\text { Change in } \\
\text { frequency in } \\
\text { Area 1 }\end{array}$ & PID & 0.12 & -0.18 & 76.54 \\
\cline { 2 - 5 } & Type 1 & 0.033 & -0.16 & 37.9 \\
\hline $\begin{array}{c}\text { Change in } \\
\text { frequency in } \\
\text { Area 2 }\end{array}$ & PID & 0.12 & -0.18 & 72.85 \\
\cline { 2 - 5 } & $\begin{array}{c}\text { Type 1 } \\
\text { Fuzzy }\end{array}$ & 0.034 & -0.17 & 34.58 \\
\hline $\begin{array}{c}\text { Change in } \\
\text { frequency in } \\
\text { Area 3 }\end{array}$ & PID & 0.28 & -0.32 & $>100$ \\
\cline { 2 - 5 } & $\begin{array}{c}\text { Type 1 } \\
\text { Fuzzy }\end{array}$ & 0.033 & -0.17 & 30.11 \\
\hline \multicolumn{2}{|c|}{} & & &
\end{tabular}

\section{Suggestion}

Fuzzy PID controller is designed and acted as controller for solving LFC problem for multi area power system, wherein future researchers may focus on designing an optimization-based design methodology using Genetic Algorithm-Fuzzy controllers or Honey Bee Mating optimization algorithm for tuning Fuzzy PI/PID controllers. The LFC design can also be done using certain techniques like Active Disturbance rejection control for Fuzzy system. The present research work may be extended with drawing extra degree of freedom framing as Type-2 Fuzzy. 


\section{Conclusions}

The present research proposed a new method for Load Frequency Control using fuzzy controller including Generation Rate Constraint (GRC) with system uncertainty parametric and various loads conditions. The simulation results proved that designed controller guarantees the robust performance such as precise reference frequency tracking and disturbance attenuation under a wide range of parameter uncertainty and area load conditions. Also, upon reducing the rule base, it has been proved that the output of reduced rule base follows the outputs of full rule base. Moreover, the Settling Time, Maximum Overshoot and Undershoot indicated the robustness of proposed Fuzzy controller has better performance as compared to conventional PID controller.

\section{References}

Castillo, O., Urias, J. \& Mellin, P. (2007). A Method for Response Integration in Modular Neural Networks Using Interval Fuzzy Logic, Proceedings IEEE FUZZ Conference, pp.247-252.

Chang, C. S. \& Fu, W. (1997). Area Load-Frequency Control Using Gain Scheduling of PI Controllers, International Journal of Electric Power \& Energy Systems, Vol.42, No.2, pp.145-152.

Chaturvedi, D. K., Satsangi, P. S. \& Kalra, P. K. (1999). Load Frequency Control: A Generalized Neural Network Approach, International Journal of Electric Power \& Energy Systems, Vol.21, No.6, pp.405-415.

Chown, G. A. \& Hartman, R. C. (1998). Design and Experiment with a Fuzzy Controller for Automatic Generation Control (AGC), IEEE Transactions on Power Systems, Vol.13, No.3, pp.965-970.

Concordia, C. \& Kirchmayer, L. K. (1954). Tie-Line Power and Frequency Control of Electric Power System, AIEE Transaction, Vol.73, Part-III-A, pp.133-146.

Gayadhar, P., Sidhartha, P. \& Ardil, C. (2009). Hybrid Neuro Fuzzy Approach for Automatic Generation Control of Two-Area Interconnected Power System, International Journal of Computational Intelligence, Vol.5, No.1, pp.80-84.

Khamsum, C., Pothiya S., Taowklang, C. \& Sangiamvibool, W. (2006). Design of Optimal PID Controller using Improved Genetic Algorithm for AGC including SMES Units, In Proceedings: International Conference on Sustainable Development: Issues and Prospects for GMS, December 6-7. 
Kothari, M. L., Kaul, B. L. \& Nanda, J. (1980). Automatic Generation Control of Hydro-Thermal System, Journal of Institute of Engineers (India), Vo1.61, pt EL2, pp.85-91.

Indulkar, C. S. \& Raj, B. (1995). Application of Fuzzy Controller to Automatic Generation Control, Electrical Machines and Power Systems, Vol.23, No.2, pp.209-220.

Mendel, J. M. (2000). Uncertain Rule-Based Fuzzy Logic Systems: Introduction and New Directions (Eds.), Prentice Hall, USA, 576p.

Nanda, J., Kothari, M. L. \& Satsangi, P. S. (1983). Automatic Generation Control of an Interconnected Hydrothermal System in Continuous and Discrete Modes Considering Generation Rate Constraints, IEEE Proceedings, Vol.130, pt D, No.1, pp.455-460.

Nanda, J. \& Sakkaram, J. S. (2003). Automatic Generation Control with Fuzzy Logic Controller Considering Generation Rate Constraint, Proceedings of 6th International Conference on Advances in Power System Control, Operation and Management, APSCOM 2003, Hong Kong, pp.770-775.

Shayeghi, H., Jalili, A. \& Shayanfar, H. A. (2005). Fuzzy PI Type Controller for Load Frequency Control Problem in Interconnected Power System, $9^{\text {th }}$ World Multi Conference on Systemic Cybernetics and Information, Orlando, Florida, USA, July 10-13, pp.24-29.

Sudha, K. R. \& Santhi, R. V. (2012). Load Frequency Control of an Interconnected Reheat Thermal System Using Type-2 Fuzzy System Including SMES Units, International Journal of Electrical Power \& Energy Systems, Vol.43, No.1, pp.1383-1392.

Sudha, K. R., Raju, Y. B. \& Sekhar, A. C. (2012). Fuzzy C-Means Clustering for Robust Decentralized Load Frequency Control of Interconnected Power System with Generation Rate Constraint, International Journal of Electrical Power \& Energy Systems, Vol.37, No.1, pp.58-66.

Surya Prakash \& Sinha, S. K. (2011). Load Frequency Control of Three Area Interconnected Hydro-Thermal Reheat Power System Using Artificial Intelligence and PI Controllers, International Journal of Engineering Science and Technology Vol.4, No.1, pp.23-37.

Talaq, J. \& Al-Basri, F. (1999). Adaptive Fuzzy Gain Scheduling for Load Frequency Control, IEEE Transactions on Power Systems, Vol.14, No.1, pp.145-150. 
Tripathy, S. C., Balasubramanian, R. \& Chandramohanan Nair, P. S. (1992). Effect of Superconducting Magnetic Energy Storage on Automatic Generation Control Considering Governor Deadband and Boiler Dynamics, IEEE Transactions on Power Systems, Vol.7, No.3, pp.1266-1273.

Yesil, E., Guzelkaya, M. \& Eksin, I. (2004). Self-Tuning Fuzzy PID Type Load and Frequency Controller, Energy Conversion and Management, Vol.45, No.3, pp.377-390. 